\title{
Schweizerische Gesellschaft für Gynäkologie und Geburtshilfe
}

http://www.sggg.ch

\author{
Präsident \\ Dr. med. Lucio Bronz \\ Ospedale Regionale Bellinzona e Valli \\ CH-6500 Bellinzona \\ Tel. +41918119 145, Fax +41918119042 \\ E-Maillucio.bronz@eoc.ch
}

\author{
Sekretär \\ Prof. Dr. med. Mario Litschgi \\ Kantonsspital Schaffhausen \\ CH-8208 Schaffhausen (Schweiz) \\ Tel. +41526 342 315, Fax +41526342398 \\ E-Mail Mario.litschgi@kssh.ch
}

Liebe Kolleginnen und Kollegen

Die Jahresversammlung 2004 der SGGG fand vom 24. bis 26. Juni in Interlaken statt. Wie schon im letzten Jahr in Lugano, konnte auch dieses Jahr mit über 600 Kongressteilnehmern ein Erfolg verbucht werden.

Zur Eröffnung wurde von Herrn Prof. Dr. O. Tönz, Luzern, ein brilliantes Gastreferat gehalten mit dem Titel «Stirbt die Schweiz aus?».

Die Tagung wurde gestaltet durch folgende Hauptthemen:

Ist der zytologische Abstrich noch zeitgemäss?

Schwangerschaft nach assistierter reproduktiver Therapie

Diagnose und Therapie der intrauterinen Pathologie

Die Vulvapathologie in der Praxis

Der SGGG-Preis 2004 für die beste wissenschaftliche Arbeit, dotiert mit CHF 20 000.-, wurde an Frau Dr. med. Viola Heinzelmann-Schwarz verliehen für die Arbeit «Overexpression of the cell adhesion molecules DDR1, claudin 3 and Ep-CAM in metaplastic ovarian epithelium and ovarian cancer».

Ziel der Studie war die Identifizierung hochregulierter Gene beim Ovarialkarzinom im Vergleich zum normalen Ovar. Es zeigte sich eine Hochregulierung aller 3 Gene bereits im metaplastischen Epithel von Inklusionszysten sowie in allen Tumorstadien. Die Resultate liefern Aufschluss über Tumorgenese, Ausbreitung und mögliche medikamentöse Behandlung des epithelialen Ovarialkarzinoms.

Frau Dr. Heinzelmann-Schwarz befindet sich in der Weiterbildung zur Fachärztin für Gynäkologie und Geburtshilfe am Departement für Frauenheilkunde, Universitätsspital Zürich. Sie arbeitete während der letzten 22 Monate am Garvan Institute of Medical Research in Sydney, Australien, und kehrt per Ende August 2004 wieder an das Departement zurück, um ihre Facharztweiterbildung abzuschliessen.

Die 3 Poster-Preise wurden wie folgt verliehen:

1. Preis: «Le polymorphisme du gène MMP2 comme facteur de risque pour le retard de croissance in utero» von S. Gremlich, D. Nguyen, D. Reymondin, S.S. Witkin und S. Gerber, Département de gynécologie et d'obstétrique, Maternité CHUV, Lausanne;

2. Preis: «Interstitielle Zystitis: It's no honeymoon!» von I. Kuchar, A. Kuhn und E. Dreher, Frauenklinik, Inselspital, Bern;

3. Preis: «Notwendigkeit eines intrapartalen sonographischen Screenings für Nabelschnurumschlingungen?» von L. Schäffer, T. Burkhardt, R. Zimmermann und J. Kurmanavicius, Klinik für Geburtshilfe, Departement Frauenheilkunde, Universitätsspital Zürich.
Weiterhin wurde ein Preis für humanitäre Projekte an Frau Pascale Hug, World Vision Schweiz, Kriesbachstrasse 30, 8600 Dübendorf, für das Thema «Mädchenbeschneidung» vergeben.

Anlässlich der Generalversammlung vom 24. Juni 2004 wurde die Ehrenmitgliedschaft der SGGG verliehen an:

Prof. Dr. med. U. Haller, Vorsteher Departement Frauenheilkunde, Universitätsspital Zürich;

Prof. Dr. med. F.A. Van Assche, University Hospital Gasthuisberg, Leuven (Belgien).

Weiterhin wurde anlässlich der Mitgliederversammlung die Arbeit des scheidenden Präsidenten und des Vorstandes verdankt und folgender Vorstand für die Amtsperiode 2004-2006 gewählt:

Präsident: Prof. Dr. med. Dr. h.c. mult. Wolfgang Holzgreve, Basel

Vize-Präsident: Prof. Dr. med. David Stucki, Fribourg

Generalsekretär: Prof. Dr. Mario Litschgi, Schaffhausen

Kassier: Dr. med. Christoph Winkler, Samedan

Vize-Sekretärin: Frau Dr. Silvia Bonanomi, Lausanne

Departement-Vorsteher Qualitätssicherung, Recht und Ethik:

PD Dr. med. Daniel Surbek, Basel

Departement-Vorsteher Medien und Kommunikation: Dr. med. Eduard Vlajkovic, Sursee

Departement-Vorsteher Bildung, Fort- und Weiterbildung: Prof. Dr. med. Patrick Hohlfeld, Lausanne

Departement-Vorsteher Koordination Facharztprüfung, VSAO: Frau Dr. Franziska Krähenmann, Zürich

Departement-Vorsteher Berufsausübung, Gesundheitspolitik, Wissenschaft, Verbindung zu den Krankenkassen: Dr. med. JeanMarc Lambercy, Lausanne

Department-Vorsteher Tarifwesen, Verbindung zu Belegärzten und Ärzten in der freien Praxis: Dr. med. Pierre Villars, Zürich

Als Beisitzer wurden weiterhin für die Präsidentenkonferenz Dr. Dieter A. Musfeld, Basel, und für den Beirat Prof. Dr. med. Gabriel Schär, Aarau, gewählt.

Damit verabschiede ich mich von Ihnen, bedanke mich für die gute Zusammenarbeit während meiner 2-jährigen Präsidialzeit im engen und im erweiterten Vorstand und wünsche dem neuen Team viel Erfolg.

Dr. med. L. Bronz, Bellinzona

\section{KARGER}

(C) 2004 S. Karger AG, Basel 